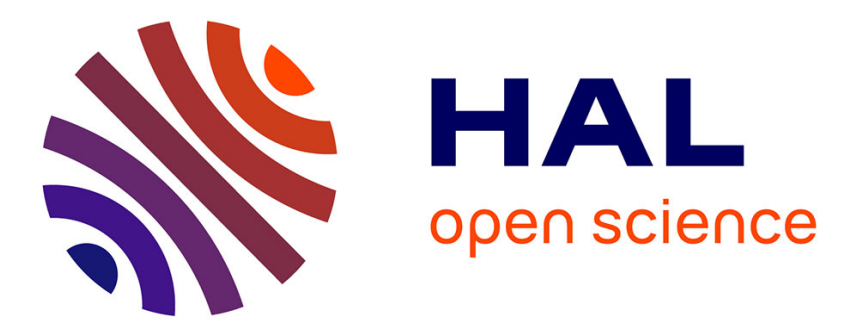

\title{
A spatio-temporal modelling approach for the study of the connectivity and accessibility of the Guangzhou metropolitan network
}

\author{
Shaopei Chen, Christophe Claramunt, Cyril Ray
}

\section{To cite this version:}

Shaopei Chen, Christophe Claramunt, Cyril Ray. A spatio-temporal modelling approach for the study of the connectivity and accessibility of the Guangzhou metropolitan network. Journal of Transport Geography, 2014, 36, pp.12-23. 10.1016/j.jtrangeo.2014.02.006 . hal-01174234

\author{
HAL Id: hal-01174234 \\ https://hal.science/hal-01174234
}

Submitted on 20 Jun 2017

HAL is a multi-disciplinary open access archive for the deposit and dissemination of scientific research documents, whether they are published or not. The documents may come from teaching and research institutions in France or abroad, or from public or private research centers.
L'archive ouverte pluridisciplinaire HAL, est destinée au dépôt et à la diffusion de documents scientifiques de niveau recherche, publiés ou non, émanant des établissements d'enseignement et de recherche français ou étrangers, des laboratoires publics ou privés. 


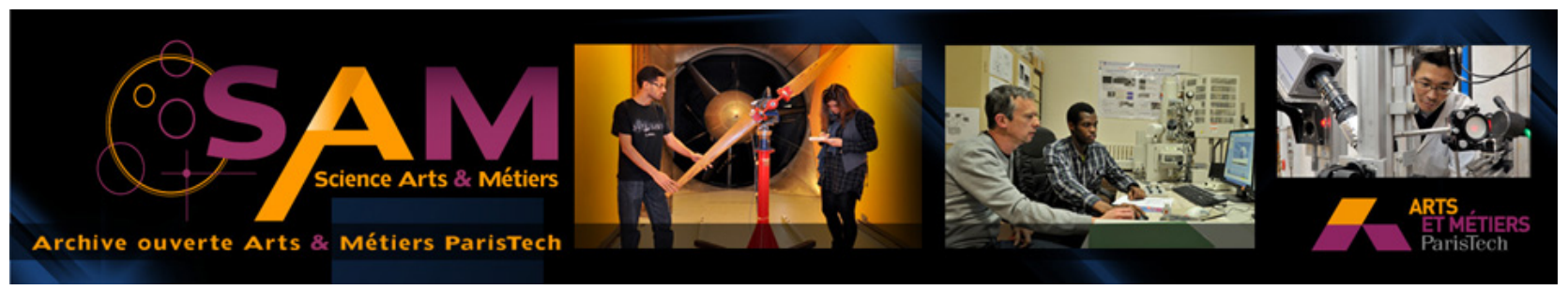

Science Arts \& Métiers (SAM)

is an open access repository that collects the work of Arts et Métiers ParisTech researchers and makes it freely available over the web where possible.

This is an author-deposited version published in: http://sam.ensam.eu

Handle ID: .http://hdl.handle.net/10985/9701

\section{To cite this version :}

Shaopei CHEN, Christophe CLARAMUNT, Cyril RAY - A spatio-temporal modelling approach for the study of the connectivity and accessibility of the Guangzhou metropolitan network - Journal of Transport Geography - Vol. 36, p.12-23 - 2014 


\title{
A spatio-temporal modelling approach for the study of the connectivity and accessibility of the Guangzhou metropolitan network
}

\author{
Shaopei Chen ${ }^{\mathrm{a}, *}$, Christophe Claramunt ${ }^{\mathrm{b}}$, Cyril Ray ${ }^{\mathrm{b}}$ \\ ${ }^{a}$ School of Public Management, Guangdong University of Finance and Economics, Guangzhou 510320, People's Republic of China \\ ${ }^{\mathrm{b}}$ Naval Academy Research Institute, BP600, F-29240 Lanvéoc-Poulmic, France
}

Keywords:

Spatio-temporal modelling

Metropolitan network

Accessibility

Connectivity

\begin{abstract}
A B S T R A C T
The urban growth of large cities in China is at a critical stage with the booming of the economy and impressive increase of the population and traffic demand. This paper studies and qualifies the growth and accessibility of a rapid rail transit network, and characterizes the relations with urban development using a spatio-temporal modelling approach. Several measures of the network topological structure, i.e., beta index $(\beta)$, cyclomatic number $(\mu)$, alpha index $(\alpha)$ and gamma index $(\gamma)$, are selected in order to examine and quantify the overall metro network growth of the city of Guangzhou in China. The results show that the current spatial connectivity of the Guangzhou's metro network is relatively low, this stressing the need to augment the reliability of the connections between the network nodes, and to increase the number of circuits in the network. A travel-time matrix is modelled and evaluates the nodes accessibility and characterizes the spatio-temporal evolution of the metro network. The spatial interaction between the different nodes of the network, as well as nodes accessibility are analyzed and derived from a potential-based model. The extension of the metro network clearly shows a dramatic tendency of positive accessibility evolution but with regional differences. In particular, the core of the city is surrounded by areas with highest accessibility values and gradually expanding outward from the core, while the locations of transfer stations have significant influence on the variation of network time-based accessibility. Taking into account different network development scenarios, the approach reveals regional accessibility differences in the metropolitan area of the city of Guangzhou, this clearly illustrating the impact of network accessibility in urban development.
\end{abstract}

\section{Introduction}

Accessibility is generally described as "the ease and convenience of access to spatially distributed opportunities with a choice of travel" (USDE, 1996). Accessibility has been an essential measure for assessing a network's spatial connectivity and evaluating travel opportunities in transportation network planning (Morris et al., 1979; Pirie, 1981). Accessibility is a multi-dimensional concept that integrates various network measures such as network connectivity and node accessibility (Garrison and Marble, 1974). Several methods have been introduced to reveal the connectivity and nodal accessibility of a given transportation network. Hansen (1959) identified accessibility as "the potential of opportunities for interaction," and provide a potential-based model to evaluate accessibility in metropolitan areas. Garrison (1960) introduced several graph theoretic concepts to analyze the topological accessi-

\footnotetext{
* Corresponding author. Tel.: +86 13560089765

E-mail address: shaopei.chen@139.com (S. Chen).
}

bility of a transportation network using accessibility indices, that is, overall network connectivity measures (i.e., beta index, association number, alpha index, gamma index) and node accessibility indices (i.e., Shimbel index and nodal degree). Transportation research has long applied these network accessibility measures based on graph theory concepts (e.g., Rühl, 1991; Blum et al., 1992; Linneker and Spence, 1992; Bowen, 2000; Li and Shum, 2001; Zhang and Lu, 2006; Jeong et al., 2007; Bharill and Rangaraj, 2008; Kreutzberger, 2008; Wang et al., 2009; Jin et al., 2009; Mavoa et al., 2012; Deng et al., 2012). The graph-based analysis applied vary, but share the objective of quantitatively studying the spatial distribution of travel opportunities based on travel time (e.g., Lutter et al., 1992; Bruinsma and Rietveld, 1993; Gutiérrez and Urbano, 1996; Deng et al., 2012), distance (e.g., Keeble et al., 1988; Spence and Linneker, 1994; Jin et al., 2009), potential accessibility model (e.g., Hansen, 1959; Geertman et al., 1995), or even structural-based approaches such as illustrated by spatial syntax studies (e.g., Cheng et al. 2007) to mention a few examples. Similar studies have been also applied to qualify the connectivity of railway networks, and to 
assess available travel opportunities in a given station's transportation environment at national and regional scales since early 1990s (e.g., Rühl, 1991; Blum et al., 1992; Murayama, 1994; Bharill and Rangaraj, 2008; Jeong et al., 2007; Kreutzberger, 2008; Wang et al., 2009; Marína and García-Ródenas, 2009; Ahlfeldta and Wendlandb, 2011; Deng et al., 2012).

Indeed, urban transportation networks such as urban rapid transit systems have essential impacts on travel opportunities, and land use change, this having a strong influence on urban spatial structures as well as socio-economic activities (Meyer and Miller, 2001). Advances in accessibility have improved spatial connectivity within urban areas and stimulated urban growth (Johnson, 1967; Jackson, 1985; Bhatta, 2010). Conversely, urban transportation accessibility is significantly influenced by, and acts on urban growth over time (Siming and Yiman, 2001). A variety of factors trigger urban transportation network development and drive changes on the accessibility they provide, including urban growth, land use change and population agglomeration, this being particularly the case for highly-densely developed cities, such as the city of Guangzhou in China. Urban development significantly increases urban mobility demand and transportation opportunities, but also brings novel traffic issues and transportation development pressure (Brueckner, 2000; Cervero, 2003; Allen and Lu, 2003; Millot, 2004; Zhou and Yan, 2005; Bhatta, 2010). Many urban planning studies have studied the causes and effects of transportation development and urban growth (e.g., Brotchie, 1991; Parker, 1995; Priemus et al., 2001; Gutiérrez, 2001; Sohn, 2006; Fan et al., 2009; Xiang and Chen, 2010; Jiang et al., 2012; Deng et al., 2012). In particular, several researches have investigated the mutual relationships between transportation system development and urban growth in the city of Guangzhou, thus demonstrating that the transportation system plays a crucial role in the evolution of the urban spatial structure. For instance, Yan and Mao (2004) discussed the relationship between, and respective evolution of the urban transport system and land use in the city of Guangzhou. Mao and Yan (2005) studied the impacts of the urban transport system on the spatial patterns, and conversely, that emerge in the city of Guangzhou. Lin and Lu (2011) showed that major transportation facilities projects implemented since 1949 have brought significant changes in the Guangzhou's urban spatial structure and urban form. However, there is still a lack of studies on the assessment of the transportation network growth and the implications of network connectivity and node accessibility, and their impact on urban development. In order to compare the evolution of the Guangzhou metro network accessibility and connectivity with the expansion of the city, there is still a need to develop a spatio-temporal modelling approach that will measure and qualify these indices and patterns.

In a previous work we introduced a multi-modal approach for the representation of the transportation system of the city of Guangzhou (Chen et al., 2009, 2011). The objective of the present paper is to extent our previous work by a spatio-temporal modelling approach that qualifies the accessibility and connectivity properties of the metro network over time, and the close relationship with urban development. Several graph-based indices and matrix analysis are applied to reveal the emerging structure and accessibility patterns of the Guangzhou metro. Several potential-based scenarios are integrated to evaluate the interactions between the different nodes of the network, this showing different attractiveness properties. Several maps derived from node accessibility measures show and illustrate the different spatio-temporal patterns and evolution of the metro network accessibility. This helps to explore the overall network connectivity and nodal accessibility transformation over time, as well as implications on regional development, and accessibility differences in the metropolitan area of the city of Guangzhou.

\section{Modelling approach}

Network connectivity and available travel opportunities are basic measures of "accessibility". Over the past years, several methods based on graph theory accessibility models have been developed in the field of transportation research. Several graph theoretic indices evaluate the topological accessibility of a given urban network and node accessibility (similar indices has been proposed to evaluate the structural properties of a given urban network by space syntax studies (e.g. Cheng et al., 2007)). Several indices have been suggested to quantify the overall network connectivity, including beta index $(\beta)$, cyclomatic number $(\mu)$, alpha index $(\alpha)$ and gamma index $(\gamma)$ (e.g., Cheng, 1998; Black, 2003; Wang et al., 2009), they are defined as follows:

- The Beta index ( $\beta$ ) gives the average number of edges (e) per node $(n)$ in a given network (Wang et al., 2009), i.e., $\beta=e / n$ $(0 \leqq \beta \leqq(n-1) / 2)$.

- The Cyclomatic number (Associated Number) gives the number of circuits to indicate a sort of gap between $e$ and $n$ while counting for the number of sub networks $q(q=1$ for a fully-connected network), i.e., $\mu=e-n+q(0 \leqq \mu \leqq(n-1)(n-2) / 2)$.

- The Alpha index $(\alpha)$ is defined as the proportion between the actual and maximal number of circuits in a fully-connecting planar network, it is given as: $\alpha=2 \mu /(n-1)(n-2)=$ $(e-n+q) /(2 n-5 q)(0 \leqq \alpha \leqq 1)$.

- The Gamma index $(\gamma)$ is the ratio between the actual and maximal number of edges: $\gamma=2 e / n(n-1)=e /[3 \times(n-2)](0 \leqq$ $\gamma \leqq 1)$.

An immediate property of these indices is that the higher their values, the higher the overall connectivity of the network. However, those indices are essentially structural and cannot reveal the functionality of a given network as it should be denoted by indices that will rather evaluate the performance of the nodes' available travel opportunities regarding the way people displacements can be performed.

In order to assess the nodal accessibility of a metro network, each metro station is abstracted to represent a node of the network. Among the indices used for the measure of nodal accessibility, Shimbel index (or Shimbel distance) has been widely examined to qualify available travel opportunities of a given node, which is a measure of a node's accessibility representing the sum of the length of all shortest paths connecting all other nodes in the graph (Black, 2003). Shimbel index can be calculated based on a distance matrix which is given by:

$D=\left[d_{i j}\right]_{n \times n}$

where $d_{i j}$ indicates the distance of shortest path between node $i$ and $j$. Therefore, Shimbel distance is the sum of the $i$ th row in matrix $\boldsymbol{D}$, i.e., the minimum amount of distances of all shortest paths from node $i$ to all other nodes:

$D_{i}=\sum_{j=1}^{n} d_{i j}$

Nevertheless, a shortest path (composed of a set of consecutive links involving different nodes) may not be the best choice for passengers, if they are required to take time to change routes. The yearbook of Guangzhou transportation development in 2012 reported more than $80 \%$ of passengers were most concerned with the time cost in a trip using metro mode (GITP, 2012). We then consider travel time as the constraint to assess nodal accessibility. To achieve this target, a time matrix $\boldsymbol{T}$ is built:

$T=\left[t_{i j}\right]_{n \times n}$ 
where each element $t_{i j}$ (in the $i$ th row and $j$ th column) denotes the shortest travel time between an origin node $i$ and a destination node $j$. Accordingly, the shortest time $\left(t_{i j}\right)$ between node $i$ and $j$ that can be reached is derived from the time table of 2012 issued by the Guangzhou Metro Corporation (GMC). As the metro network is a fully-connected graph, $t_{i j}$ is given as finite as there is a direct or by transfer route between any node $i$ and $j$. As a result, the minimum amount of travel time from node $i$ to all other nodes (i.e., the nodal degree at node $i$ ) is the sum of the $i$ th row in the matrix $\boldsymbol{T}$, and then given by:

$T_{i}=\sum_{j=1}^{n} t_{i j}$

where for small $\boldsymbol{T}_{\boldsymbol{i}}$ values, it is relatively convenient for a passenger is to reach destinations started from node $i$ to all the other nodes. Moreover, the minimum travel time regarding all possible origindestination transfers in the network is given by the sum of nodal degrees at all nodes, and thus described as:

$S=\sum_{i=1}^{n} T_{i}$

Based on $\boldsymbol{T}_{\boldsymbol{i}}$ and $\boldsymbol{S}$, the nodal time-based accessibility coefficient at a given node $i$ is given by the ratio of $\boldsymbol{T}_{\boldsymbol{i}}$ on that node $i$ to the average of nodal degrees in the network, and it is given by:

$A_{\mathrm{ti}}=\frac{T_{i}}{\left(\sum_{j=1}^{n} T_{j}\right) / n}$

A lower value of $\boldsymbol{A}_{\boldsymbol{t} \boldsymbol{i}}$ means a better nodal accessibility at the node $i$. If $\boldsymbol{A}_{\boldsymbol{t} \boldsymbol{i}}>1$, the nodal time-based accessibility coefficient at that node $i$ is below the network average (conversely, the coefficient $\left(\boldsymbol{A}_{\boldsymbol{t} \boldsymbol{i}}<1\right)$ is above network average). Small $\boldsymbol{A}_{\boldsymbol{t} \boldsymbol{i}}$ reflect good time-based accessibilities. As for transfer indices, the index $\boldsymbol{A}_{\boldsymbol{t} \boldsymbol{i}}$ tends to favor nodes near the center of the network (but in a less significant way).

A potential-based measure model of spatial accessibility was first introduced by Hansen (1959). This model is derived from social physics, and assumes some analogies between physical (e.g. Newton's Law of Gravitation) and social phenomena (Salze et al., 2011). For example, Stewart (1941) revealed the influence of the population between two spaces was inversely proportional to the distance between them, and thus proposed an inverse distance weighting function. Since then, distance weighting functions have been developed for spatial interaction and potential-based modelling. Generally, a potential accessibility model is given by:

$P_{i}=\sum_{j=1}^{n} M_{j} C_{i j}^{-\alpha}$

where $\boldsymbol{P}_{\boldsymbol{i}}$ denotes the potential accessibility index at node $i ; M_{j}$ is an opportunity (i.e., the weight in the network) at node $j ; C_{i j}$ is the distance (or time) between node $i$ and $j$; $C_{i j}^{-a l p h a}$ (the inverse power) can refer to "frictional effect of space" (where $\alpha$ is the frictional index and its value is usually assigned as 1 ), and can be seen as people's willingness to travel according to trip purpose or destination attractiveness. This implies that the easy and convenience to reach the destination node $j$ from a given node $i$ is not only obstructed by the negative impact of the spatial constraints (e.g., distance or travel time) between two nodes, but also improved by the positive impact of the opportunities at the destination node. The latter significantly shows the characteristics of gravity in the spatial interaction between two nodes. This means that a potential-based measure model is able to overcome the limitations of the most frequently used indices such as the distance or time of shortest path and the count of opportunities within a given neighborhood (Salze et al., 2011).

Currently, potential models have been widely applied to the evaluation of spatial accessibility to the distribution of business service facilities. Such approaches can be used to qualify the spatial interaction between metro stations and the nodal potential accessibility simulated by their attractiveness (i.e., opportunities). The expanding metro network provides rapid and wide-reaching connections accelerating resident trip. In order to understand the basic patterns that emerge from the network, and the socio-economic and travel implications in the areas around the station, information on passenger flows in a given period is required. Therefore, the passenger flow volume per day at a metro station is weighted in the metro network, to evaluate the interaction and nodal potential accessibility by a potential model, which is given as (in fact the passenger flow at a given node for a given interval of time gives a sort of evaluation of the attractiveness of this node in the network):

$A_{p i}=\sum_{j=1}^{n} \frac{V_{j}}{t_{i j}}$

where $\boldsymbol{A}_{\boldsymbol{p} \boldsymbol{i}}$ is the extended potential accessibility index at a given node, and the higher value of $\boldsymbol{A}_{\boldsymbol{p} \boldsymbol{i}}$ means a better potential nodal accessibility at node $i ; t_{i j}$ denotes the shortest travel time between node $i$ and $j$; $m$ denotes the number of nodes considered in the network, $V_{j}$ is an attractiveness/opportunities qualitative (i.e., weight) of destination node $j$, and given by:

$V_{j}=\frac{G_{k}}{\left(\sum_{l=1}^{m} G_{l}\right) / m}$

where $\boldsymbol{G}_{\boldsymbol{k}}$ is the passenger flow per day at a station metro (data for passenger flows is collected from the yearbook issued by the Guangzhou Metro Company (GMC, 2012)).

\section{Guangzhou's metro network expansion}

\subsection{Study area}

The large administrative area of the city of Guangzhou comprises ten urban districts (i.e., Tianhe, Baiyun, Huanpu, Haizhu, Liwan, Yuexiu, Huadu, Luogang, Panyu and Nansha) and two suburban counties (i.e., Conghua and Zengcheng), with a total area of 7434 square kilometers (Statistics Bureau of Guangzhou, 2012). Amongst these districts, Liwan, Haizhu and Yuexiu are the historically downtown centers of the city with high population density (exceeds 12 thousand persons per square $\mathrm{km}$ ), where the municipal and provincial governments and many academic institutions are located. Tianhe is the new downtown centre, and has attracted a lot of mobility and commerce activities. The historical and new downtown centers form the "core" of the city. Other districts, such as Huanpu, Bainyun, Panyu and Luogang, surround the core of the city.

Since the late 1970s, the city of Guangzhou has maintained a rapid economic development. This provides opportunities to develop its urban transportation systems, involving roads network, bus network and metro network, for facilitating passenger transportation over the city. Presently, the metro network in the city of Guangzhou has extended from the core area to some districts around the core, including Baiyun, Panyu and Huanpu. Our research selects the core of the city and the districts around the core as the study area (Fig. 1).

\subsection{Metro network expansion}

The metro network in Guangzhou has been progressively constructed since 1993. Nowadays, it has 8 lines with a total length of $232 \mathrm{~km}$. During its development, the years of 1999, 2002, 2005, 2009 and 2011 are the significant temporal points. At each timestamp, new lines were established to reshape the spatial 


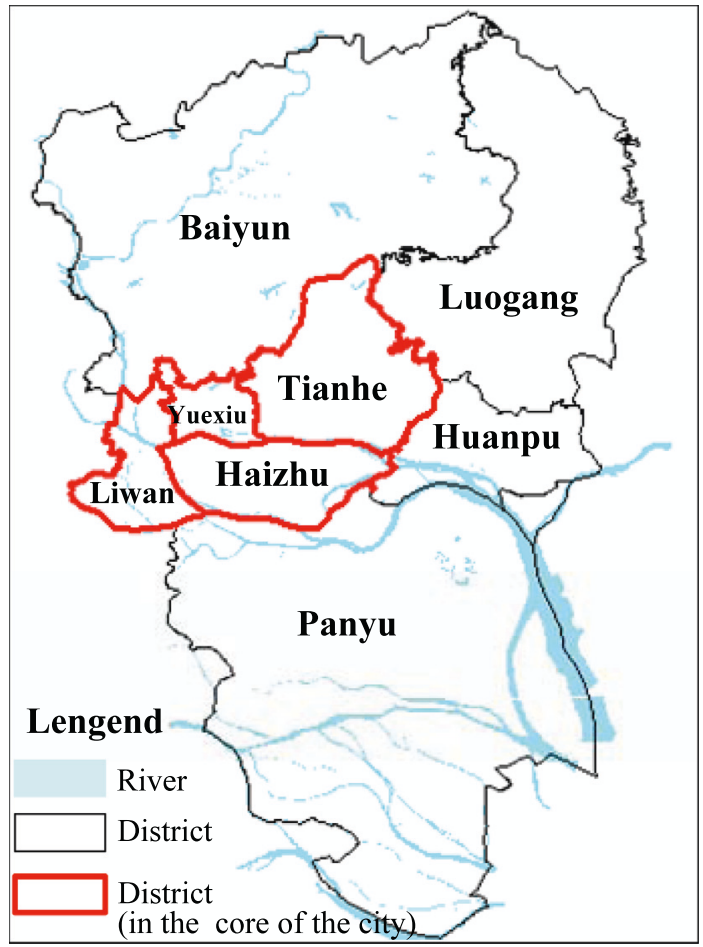

Fig. 1. Study area.

structure of the metro network. Taking into account the influence on the network spatial expansion and structure at each temporal point, the Guangzhou's metro network development may be taken apart into three stages, i.e., preliminary construction
(1999-2002), networking (2005-2009), and network intensification (2011).

\subsubsection{Preliminary construction (1999-2002)}

With the reform and opening in China since 1979, the society and economy stepped into the recovery period. This leads to a consecutive and rapid urban development in the cities of China. In 1993, the city of Guangzhou started to build its first metro line (named as Line 1), and thus opened in 1999. In 2002, another line (i.e., Line 2) was also in operation. In this stage, Line 1 and Line 2 went through the "core" area of the city of Guangzhou (Fig. 2), and shaped a "+" frame with the transfer station of "Gongyuan Qian".

\subsubsection{Networking (2005-2009)}

In 2005, the development of Guangzhou's metro network stepped into the networking stage. Three new metro lines were constructed and in operation, i.e., Line 3, Line 4 and Line 5, during 2005-2009. These lines and Line 1 and Line 2 constituted the skeleton of the metro network (Fig. 3). The spatial distribution of the network expands outside the core area of the city of Guangzhou, and tended to south and west districts, which are Panyu and Huangpu districts, respectively.

\subsubsection{Network intensification (2011)}

After the accomplishment of the metro lines networking, Guangzhou focused on the network intensification and the optimization of the lines organization. In 2011, the branch of Line 3 running from Linhe Xi to Airport South was opened. Meanwhile, the intercity metro line (i.e., Line GF) to connect the cities of Guangzhou and Foshan was constructed and in operation. Moreover, an underground line based on Automated People Mover (APM) system (i.e., Line APM) was established to serve the central business district of Tianhe District, and connected to Line $\mathbf{3}$ with the station of Linhe xi and Chigang Pagoda, respectively.

Importantly, three segments, first one running from Changgang to Guangzhou South Railway Station, second one from Sanyuan Li to Jiahe Wanggang, and last one from Changgan to Fenghuang

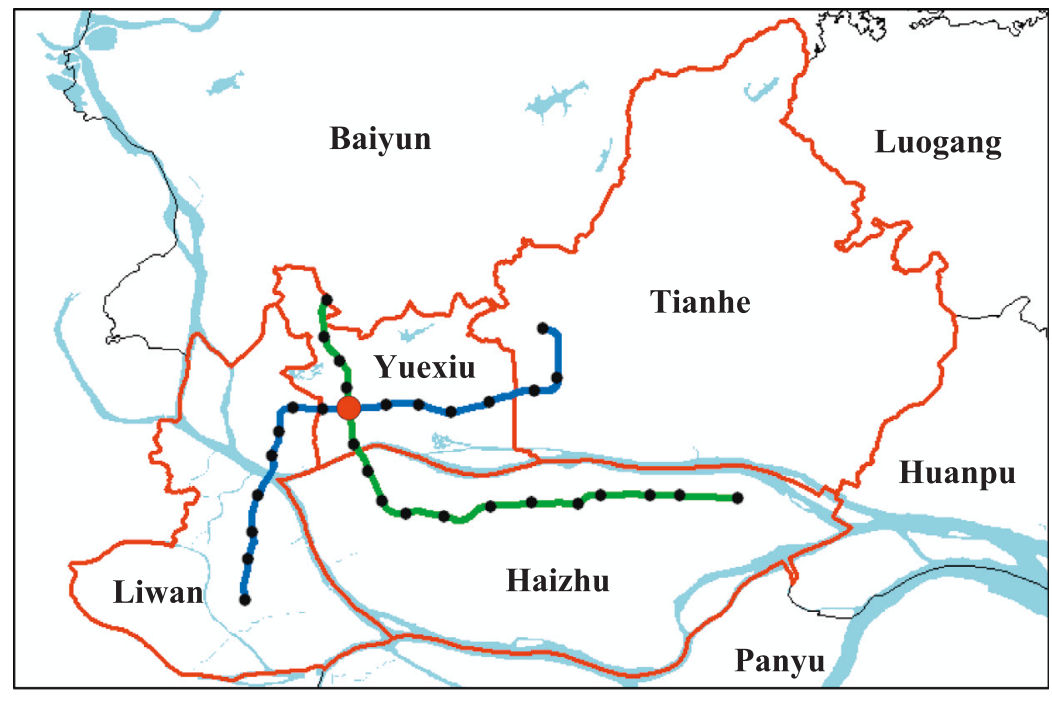

\section{Lengend}

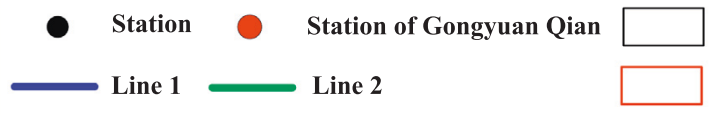

District

River

Core of

the city

Fig. 2. Distribution of Line 1 and Line 2 in 2002. 


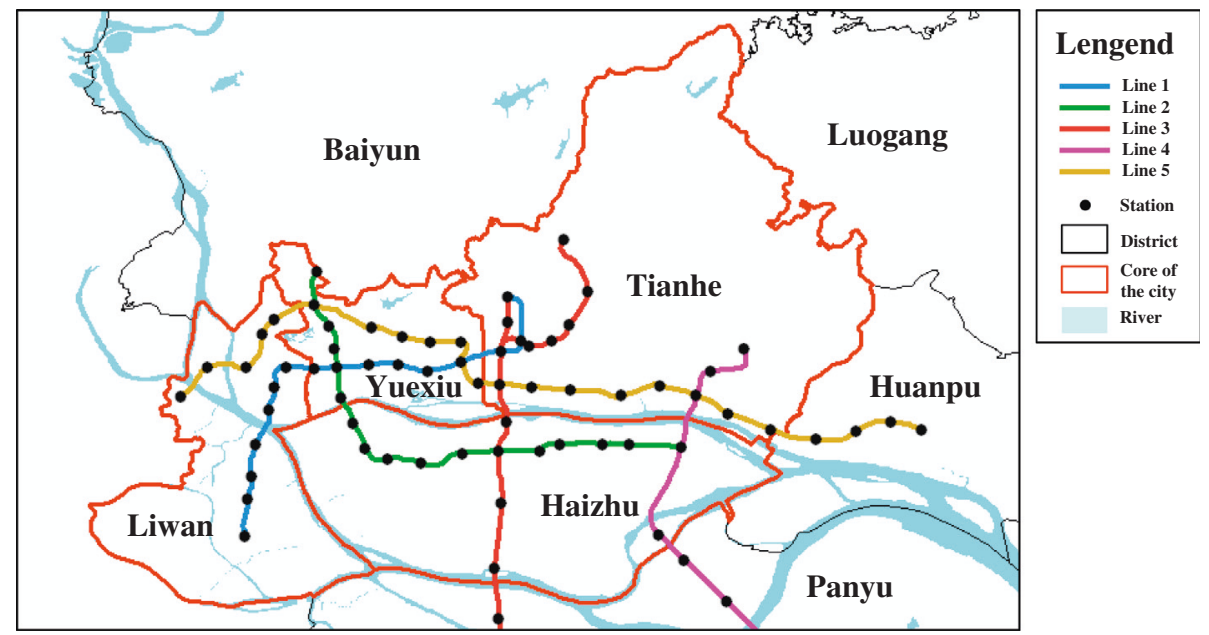

Fig. 3. Spatial distribution of the Guangzhou's metro network in 2009.

Xincun, were constructed and opening in this stage. In order to improve the service efficiency and capabilities of the overall network, the segments and stations of Line $\mathbf{2}$ were reorganized. The previous Line 2 was divided into two parts at the station of Xiaogan. One part (Sanyuan Li-Jiannan Xi) connected the segments of Changgan -Guangzhou South Railway Station and Sanyuan Li-Jiahe Wanggang to organize the new Line 2, and joints the branch of Line 3 at the station of Jiaohe Wanggang. The other part (XiaogangWansheng Wei) connected to the segment running from Changgan to Fenghuang Xincun for composing Line 8. The transfer station of new Line $\mathbf{2}$ and Line $\mathbf{8}$ is the station of Changgan. As shown in Fig. 4, at this stage the metro network was significantly intensified in the core area of the city, and extended to the district of Baiyun.

\section{Spatiotemporal evolution of accessibility}

\subsection{Evaluation of overall network connectivity}

Table 1 gives an overall view of the spatial extension of the metro network in the city of Guangzhou at the temporal points of 1999, 2002, 2005, 2009 and 2011. This shows that the speed of

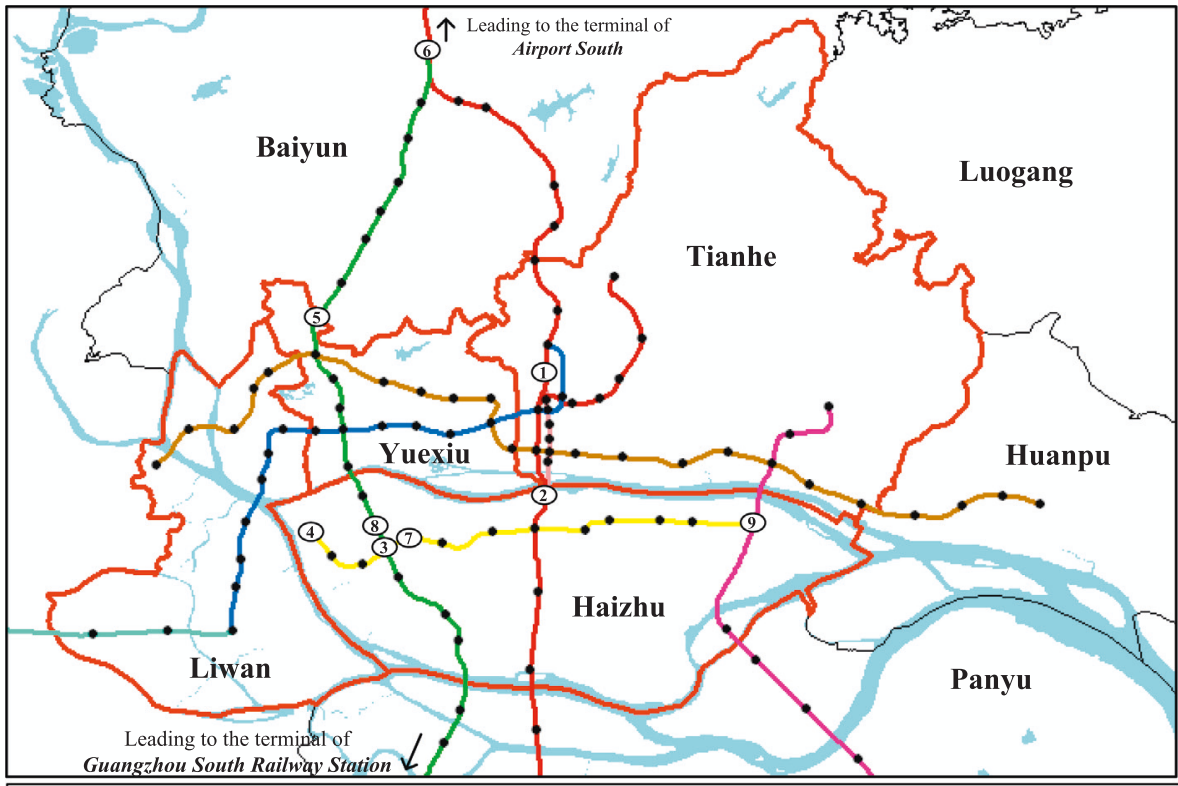

\section{Lengend}

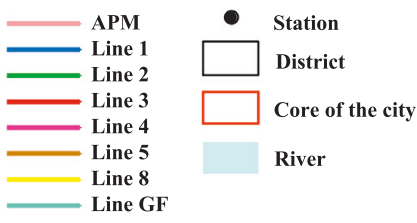
(1) Linhe $x i$
(2) Chigang pagoda
(3) Changgang
(4) Fenghuang Xincun
(5) Sanyuan $\mathrm{Li}$
(6) Jiahe Wanggang
(7) Xiaogan

(8) Jiannan Xi

(9) Wansheng Wei

Fig. 4. Spatial distribution of the Guangzhou's metro network in 2010. 
Table 1

Spatial extension of the metro network in Guangzhou.

\begin{tabular}{lllcccc}
\hline Year & Lines & Stations & Rate $(\%)$ & Links & Rate $(\%)$ & Route length $(\mathrm{km})$ \\
\hline 1999 & 1 & 16 & 12.4 & 15 & 11.2 & 18.5 \\
2002 & 2 & 32 & 24.8 & 31 & 23.1 & 41.8 \\
2005 & 4 & 62 & 48.1 & 62 & 46.3 & 121.7 \\
2009 & 5 & 82 & 63.6 & 85 & 63.4 & 152.9 \\
2011 & 8 & 129 & 100 & 134 & 100 & 231.8 \\
\hline
\end{tabular}

Table 2

Evaluation of the metro network growth.

\begin{tabular}{llllll}
\hline Index & Year & & & & \\
\cline { 2 - 6 } & 1999 & 2002 & 2005 & 2009 & 2011 \\
\hline$\beta$ & 0.94 & 0.94 & 1 & 1.04 & 1.04 \\
$\mu$ & 0 & 0 & 1 & 4 & 6 \\
$\alpha$ & 0 & 0 & 0.01 & 0.03 & 0.02 \\
$\gamma$ & 0.36 & 0.34 & 0.34 & 0.55 & 0.35 \\
\hline
\end{tabular}

network extension was constantly accelerating. Particularly in 2011, three new lines were established and opened. This simulated a sharp rising of more than $50 \%$ of the number of stations and the route length of the network. This should have a large influence on the spatial connectivity of the overall network, and can be reflected by the change of the network's topological properties. Table 2 shows the topological properties of the overall metro network at different temporal points by the four indices previously introduced, i.e., beta index $(\beta)$, cyclomatic number $(\mu)$, alpha index $(\alpha)$ and gamma index $(\gamma))$. The figures that emerge show that the connectivity of the overall metro network in the city of Guangzhou reveals a tree network structure, and its quality was at a lower level in the stage of preliminary construction (1999-2002), as $\beta \leqslant 1$ and $\mu=0$. In the stage of networking (2005-2009), with the opening of the branch of Line 3, the network appears as a cyclomatic network due to $\beta=1$ and $\mu=1$. And then, the number of circuits (i.e., $\mu$ ) reaches the value of 6 in the stage of network intensification (2011). This reveals that the spatial structure of the network has been relatively optimized, and the connectivity had been improving accompanied by the growth of the metro network. However, it appears that the values of $\alpha(\leqslant 0.03)$ and $\gamma(\leqslant 0.55)$ are relatively lower during the network expansion from 1999 to 2011. This indicates both of the actual numbers of circuits and edges are very small in the current network. This emphasizes a need to augment the reliability ofl inkage between nodes for increasing the number of circuits in the network, and thus improve the connectivity quality of the overall network which is still at a relative lower level.

\subsection{Evaluation of nodal accessibility}

The evaluation of the overall metro network connectivity shows several trends regarding the growth of the network in three stages.
However, the change of the overall network topological properties cannot characterize the opportunities at a node. To complete the study, a matrix analysis- and potential model-based nodal accessibility measures are applied to analyze the opportunities at a given node (metro station), and to assess its accessibility in the Guangzhou's metro network.

\subsubsection{Evaluation and spatio-temporal evolution of nodal accessibility based on matrix}

A travel time matrix $\boldsymbol{T}$ is derived to measure the temporal impedance between nodes (metro stations) in the Guangzhou's metro network. On the basis of this matrix $\boldsymbol{T}$, the accessibility coefficient $\left(\boldsymbol{A}_{\boldsymbol{t}}\right)$ at every metro station is calculated to reflect its travel available opportunities relative to the others stations. As mentioned above, if $\boldsymbol{A}_{\boldsymbol{t} \boldsymbol{i}} \leqslant 1.0$, a node's accessibility is above the network average. Fig. 5 illustrates the increasing trends of the number of stations with $\boldsymbol{A}_{\boldsymbol{t} \boldsymbol{i}} \leqslant 1.0$ and $\boldsymbol{A}_{\boldsymbol{t} \boldsymbol{i}}>1.0$ in three development stages (i.e., preliminary construction, networking and network intensification). The finding reflects that the nodal accessibility is gradually improved with the network growth, as the number of stations with $\boldsymbol{A}_{\boldsymbol{t} i} \leqslant 1.0$ has a more sharper increase trend than the number of stations with $\boldsymbol{A}_{\boldsymbol{t} i}>1.0$.

To explore the spatial pattern and temporal evolution of the metro network accessibility in the city of Guangzhou, contours maps are generated based on time-based accessibility coefficients $\left(\boldsymbol{A}_{\boldsymbol{t} i}\right)$ at all stations in the network. Fig. 6 illustrates the spatial pattern of the Guangzhou's metro network that emerges in the stages of preliminary construction, networking and network intensification, respectively. The results that emerge show the following patterns:

- The area coverage of the metro network consistently expands over time. As shown by the contour maps in the three stages of the network development, the metro network stretched around Yuexiu district. Also, the contours became smoother gradually, and thus formed a more compact network.

- The stations with $\boldsymbol{A}_{\boldsymbol{t} \boldsymbol{i}} \leqslant 1$ are intensively located in the core area of the city over the time. From a spatio-temporal perspective, the areas with $\boldsymbol{A}_{\boldsymbol{t} \boldsymbol{i}} \leqslant 1$ increasingly expanded from Yuexiu district to other districts in the core area. In the stage of preliminary construction, only Yuexiu and parts of Liwan and Haizhu, were covered by the contours of $\boldsymbol{A}_{\boldsymbol{t} i} \leqslant 1$. In the stage of networking, Panyu and parts of Tianhe joined the list and in the stage of network intensification, parts of Baiyun also joined. Importantly, the $\boldsymbol{A}_{\boldsymbol{t} \boldsymbol{i}}$ of the easiest accessible node declines slightly over the time. This implies that the "aggregation" of the metro network is increasing.

- As shown by the contours maps, the spatial pattern reflected by time-based accessibility gradually evolved into a concentric circle spatial structure, but the spatial distributions of the contours were not even in different development stages. From a spatial perspective, in the stage of preliminary construction, the spatial

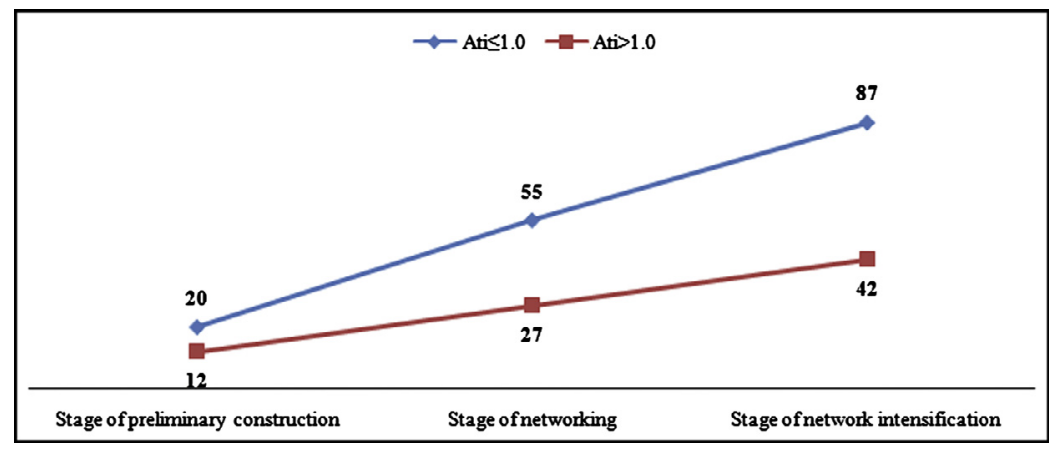

Fig. 5. Increasing trends of the number of stations with $\boldsymbol{A}_{\boldsymbol{t} \boldsymbol{i}} \leqslant 1.0$ and $\boldsymbol{A}_{\boldsymbol{t} \boldsymbol{i}}>1.0$. 


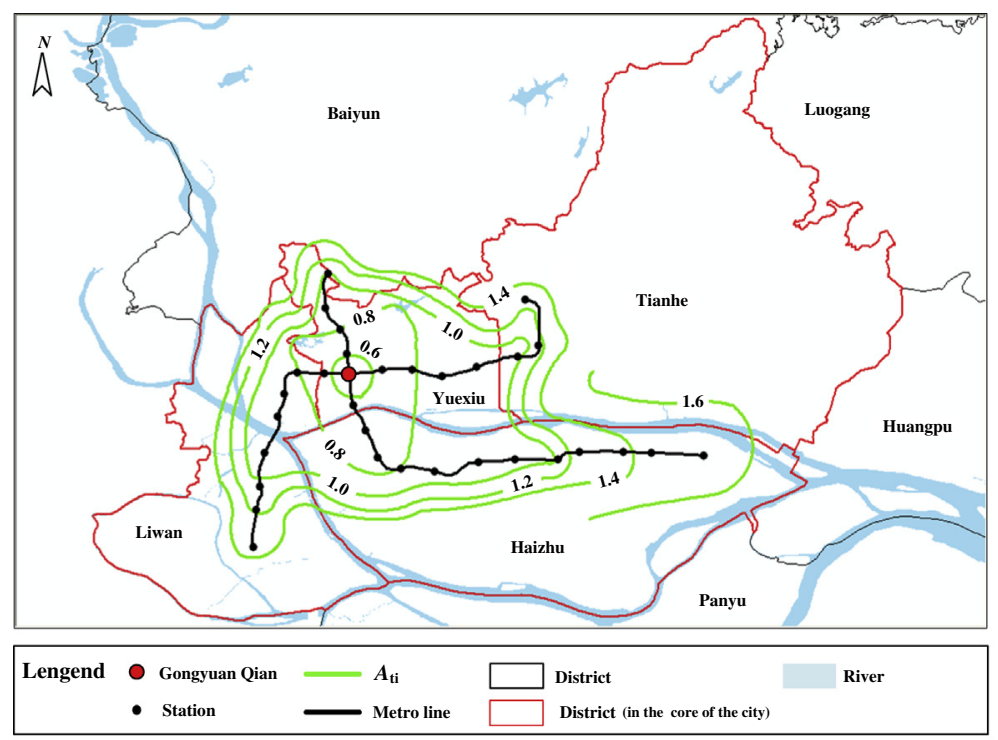

(a) The stage of preliminary construction

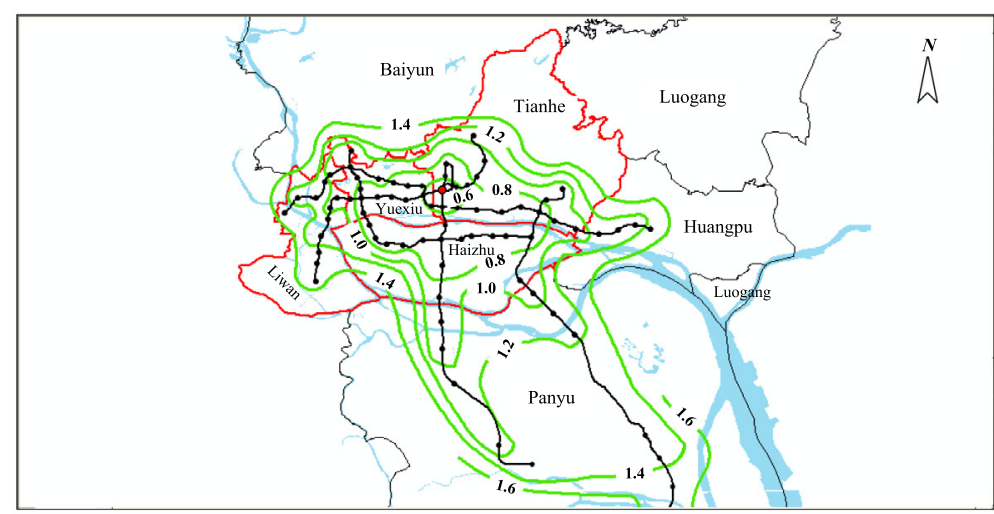

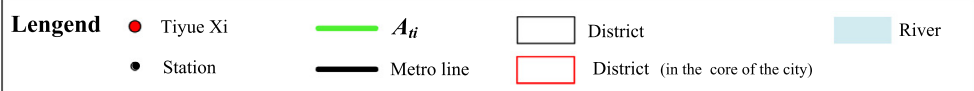

(b) The stage of networking

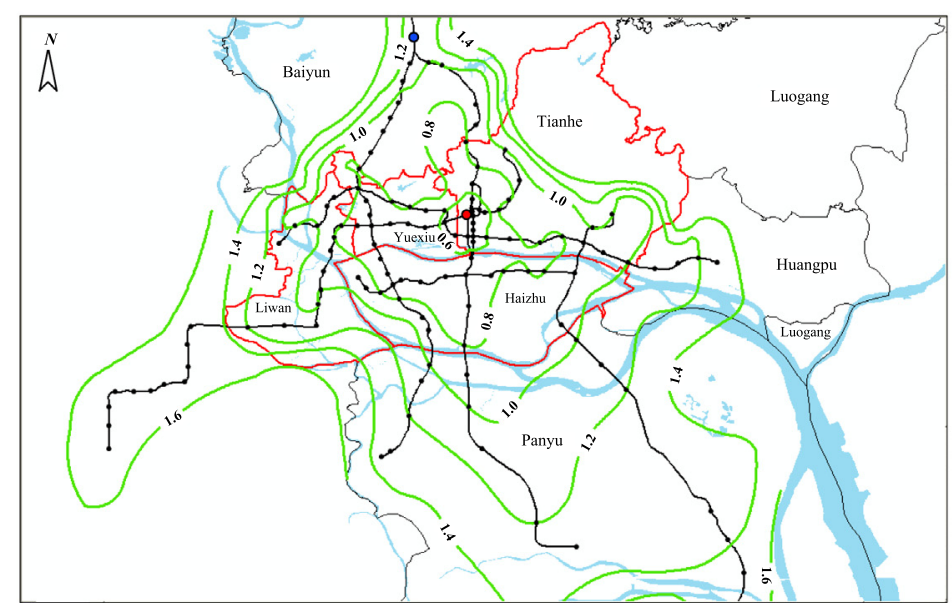

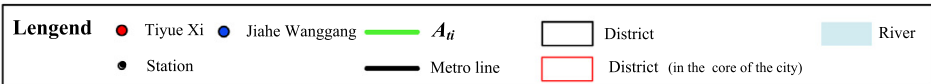

(c) The stage of network intensification

Fig. 6. Spatial patterns and temporal evolution of the Guangzhou's metro network accessibility. 
distribution of the contours with $\boldsymbol{A}_{\boldsymbol{t} \boldsymbol{i}} \leqslant 1.0$ was few and scattered. This reveals that the accessibility in these areas covered by the contours with $\boldsymbol{A}_{\boldsymbol{t} \boldsymbol{i}} \leqslant 1.0$ has a tendency toward gradual variation (Fig. 6(a)). To the contrary, in the areas where the distribution of the contours with $\boldsymbol{A}_{\boldsymbol{t} \boldsymbol{i}}>1.0$ were crowded together, this implies that the accessibility has a clear trend toward sharp decline with the augment of $\boldsymbol{A}_{\boldsymbol{t} \boldsymbol{i}}$. This demonstrates the influence and characteristics of the "+" frame of network spatial construct on accessibility in the stage of preliminary construction. With the expansion of metro network, in the stages of networking and network intensification, the tendency toward gradual variation extended to the south areas, particularly to Panyu district, as in these two stages there were three lines expanded from the core area of city into the district of Panyu (Fig. 6(b and c)). All of these stress the uneven spatial development of the metro network in the city of Guangzhou over the time, and explore the cause and effect on the differences of urban regional accessibility.

- In the stage of preliminary, Gongyuan Qian was the transfer station of Line 1 and Line 2, and was the geometric center of the metro network. But with the extension of the network, the geometric center moved clearly towards Tiyu $\mathbf{X i}$, which had the best (lowest) accessibility coefficient $\left(\boldsymbol{A}_{\boldsymbol{t} i} \leqslant 0.6\right)$ in the stages of networking and network intensification (Fig. 6(b and c)). Tiyu $\boldsymbol{X} \boldsymbol{i}$ is the transfer station of Line $\mathbf{1}$ and Line $\mathbf{3}$ and located in the district of Tianhe where the speed of urban construction and population increase has been booming in the city of Guangzhou since 2000. Therefore, more and more mobility and commerce activities were attracted in Tianhe district over the years. Currently, the economic and commercial center in the city of Guangzhou has moved from Yuexiu district to Tianhe district. Moreover, the movement of geometric center of the metro network coincides with the trend of the urban development. All of these also indicate the interaction between metro network growth and urban development.

- According to the accessibility variation in space which is reflected by the spatial distribution of contours, the accessibility for the areas along Line $\mathbf{3}$ and Line $\mathbf{4}$ in Panyu district were not improved remarkably in the stage of networking (Fig. 6(b)), and the same happened when new Line 2 was in operation in the stage of network intensification (Fig. 6(c)). But in the stage of network intensification, areas with sharp improvement in accessibility shifted gradually from the core of the city to the south of Baiyun district where the branch of Line $\mathbf{3}$ and new Line 2 (two lines are interconnected by the station of Jiahe Wanggang) were in operation (Fig. 6(c)). This shows the roles of transfer station in the difference between regional accessibility evolutions, as the lines in Panyu district were not interconnected with each other.

A specific case is selected to demonstrate the impacts of a transfer station on the nearby stations' accessibility. Fig. 7 illustrates the locations of all transfer stations in the city of Guangzhou in the stage of network intensification. Regarding the matrix $\boldsymbol{T}\left(\boldsymbol{T}=\left[t_{i j}\right]_{n \times n}\right)$, while the origin (node $i$ ) is identified as a given station, the elements in the $i$ th row, i.e., $t_{i j}(j=1,2, \ldots, n)$ denotes the actual travel time between the given origin station and all destination stations. As the transfer station of Tiyue Xi has been the geometric centre (with the best accessibility coefficient) at this stage, it is identified as the original node to obtain the values of $t_{i j}$ at all other stations, and then contours are generated (Fig. 7). The results found that the contours expanded outward from the geometric center (i.e., Tiyue Xi) in the network, and the contours with $t_{i j} \leqslant 30$ min covered all transfer stations. Particularly, the contours were clearly convex when they are near transfer stations. This demonstrates the accessibility of a transfer station has a larger amount of radiant energy to extend widely in space.

\subsubsection{Evaluation of nodal potential accessibility based on potential} model

In order to examine the nodal spatial interaction and attractiveness with other nodes, the potential-based model, as introduced above, has been applied based on the measure of passenger flow volumes available in 2011. It is noteworthy to remark that the geometric center of the network, which has the best potential accessibility, is the station of Sun Yat-sen Memorial Hall (Fig. 8). This station is not a transfer station, but actually shows the great attractiveness to all other stations depending on its central location in the network, and particularly the high density of population and infrastructure facilities distribution in the areas around the station. Nevertheless, Fig. 8 illustrates that most of stations with secondbest nodal potential accessibility are located in the areas around Tiyue Xi, where has a perfect spatial structure of the network, i.e., there were four lines, including Line 1, Line 5, Line 3 and Line APM, joints with each other. Importantly, the areas are the highest developed regions in the city of Guangzhou.

Furthermore, a contour map in the context of nodal potential accessibility has been drawn in Fig. 9. It shows that there are two peaks, i.e., centers in the spatial pattern of nodal potential accessibility. Also, the nodal potential accessibility extends outwards and gradually decays with the increasing of distance with the centers. This indicates that the inverse temporal weighting characteristics in the nodal potential accessibility spatial variation.

Generally, the potential accessibility at a metro station is not only correlated with the spatiotemporal properties between stations, but also catalyzed by the level of urban development in the areas around the station. In the report of Guangzhou transportation development yearbook in 2012 issued by the Guangzhou Institute of Transportation Planning (GITP, 2012), the study area is districted into three level urban development zones (high level zone, secondary level zone and low level zone) according to the

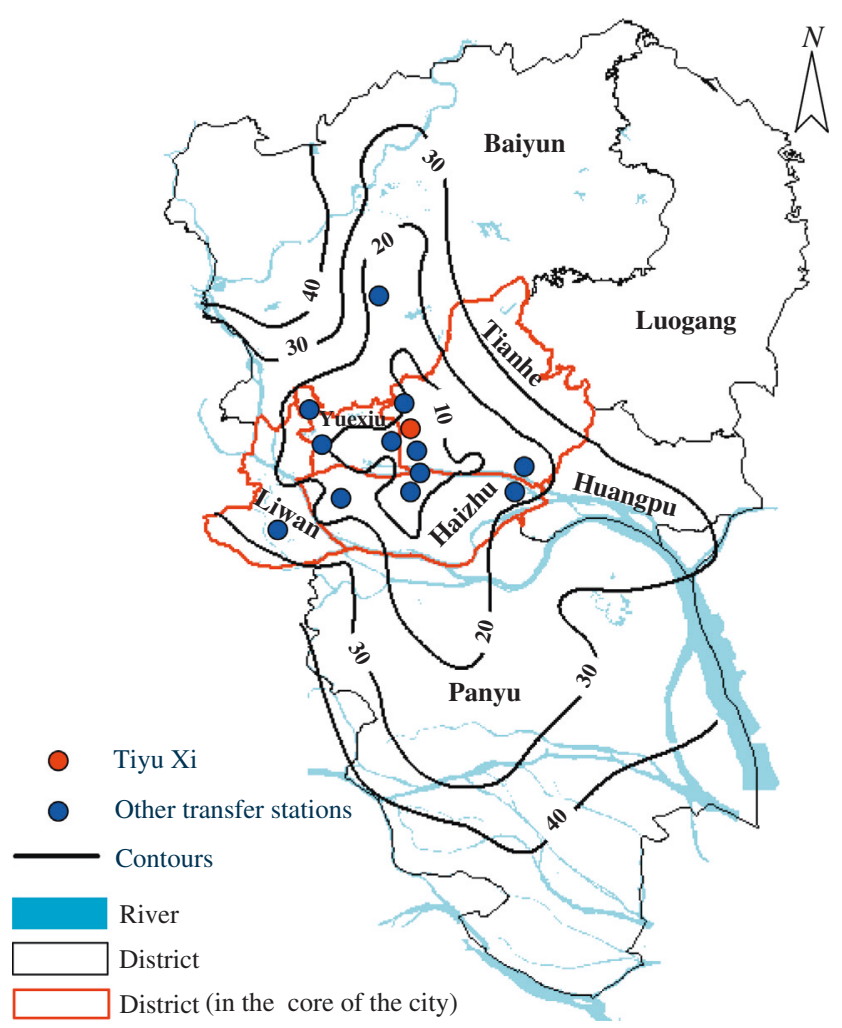

Fig. 7. Locations of transfer stations and contours of $t_{i j}$ between Tiyu Xi and all other stations. 


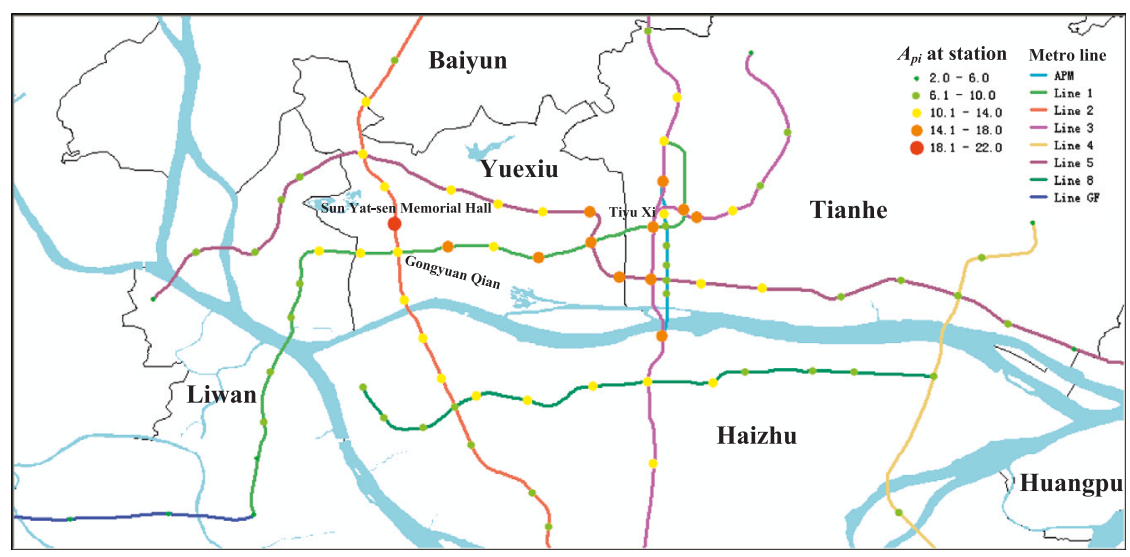

Fig. 8. Distribution of the stations with various nodal potential accessibility levels.

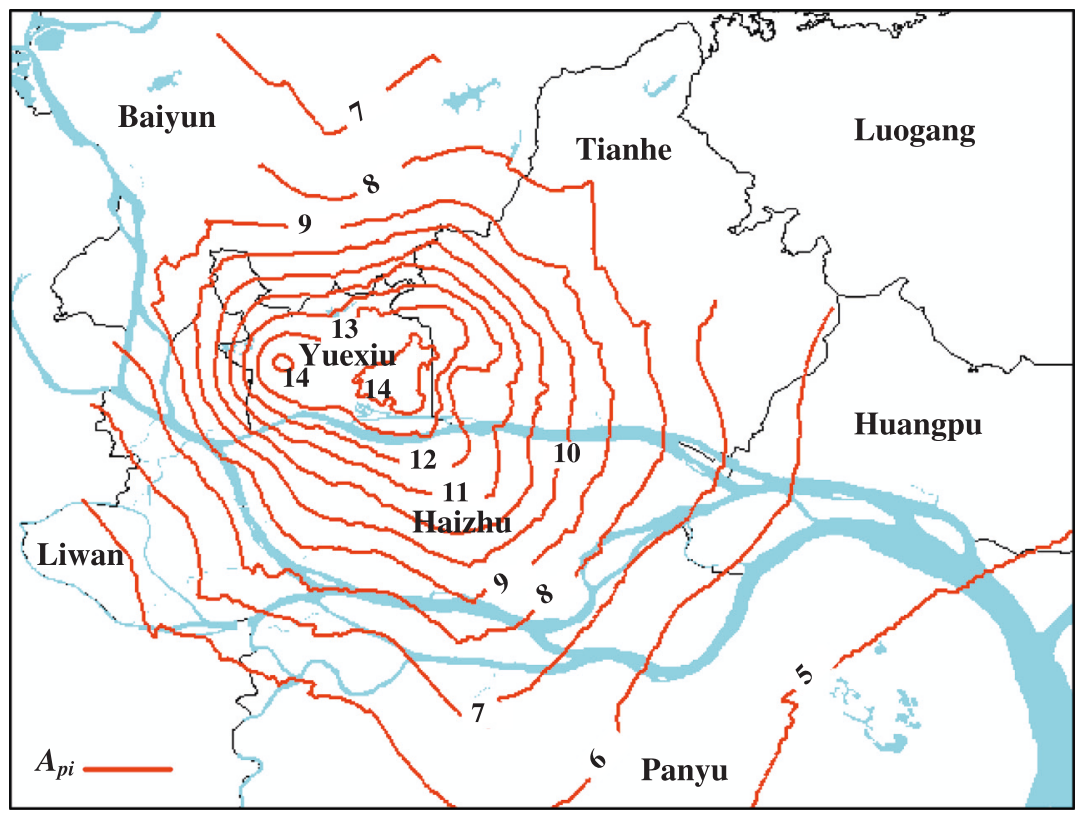

Fig. 9. Contour map for illustrating the spatial pattern of nodal potential accessibility.

spatial distributions of transportation infrastructure facilities density, population and traffic flows. This reveals that the spatial trend of the nodal potential accessibility variation clearly matches the distribution pattern of three level zones. Also, the stations with the best, second-best and secondary levels of nodal potential accessibility are located in the high level zone (Fig. 10).

\section{Relations with urban development}

During the development of the metro network, the city of Guangzhou witnessed a dramatic spatial expansion of the urban built-up area, and augment of the population. As shown in Fig. 11, the urban built-up area and population increased rapidly with a $10 \%$ annual growth rate over the time. Fig. 12 shows the expansion of the mixed-use residential and commercial areas in the three stages of metro network development. The process of the urban built-up area expansion and population increase in Guangzhou demonstrates the core of the city is surrounded by the mixed-use residential and commercial areas rapidly expanding outward from the core. Meanwhile, the trend of metro network extension is illustrated to clearly match the residential and commercial areas expansions over the time.
Indeed, the accessibility provided by the metro network has led to a significant influence on the increase and distribution of the population in the city of Guangzhou over the time. Fig. 13 shows the spatial evolution of the population density, as well as the contours of time-based nodal accessibility in the three stages of metro network development in a composite perspective. The results reveal that the areas with higher population density (above 8000 persons per square kilometer) are intensively distributed in the core of the city, especially in the district of Yuexiu and the areas outward. From 2002 to 2011, a significant increasing of the population density occurred in the area around the metro station of Tiyue Xi, which is located in Tianhe district (Statistics Bureau of Guangzhou, 2012). As mentioned above, the station of Tiyue Xi has been the geometric center of the network with the best (lowest) accessibility coefficient $\left(\boldsymbol{A}_{\boldsymbol{t} \boldsymbol{i}}=0.59\right)$ since 2009. Fig. 13 also demonstrates this geometric center is surrounded by the areas with relatively high-density population, as well as the areas with progressively lower-density population spreading outward from the center. This shows that the nodal time-based accessibility development can catalyze the population distribution and density change in the area around a metro station. Furthermore, Fig. 13 shows the change of the contour with $\boldsymbol{A}_{\boldsymbol{t} \boldsymbol{i}}=1.0$ coincides with the 


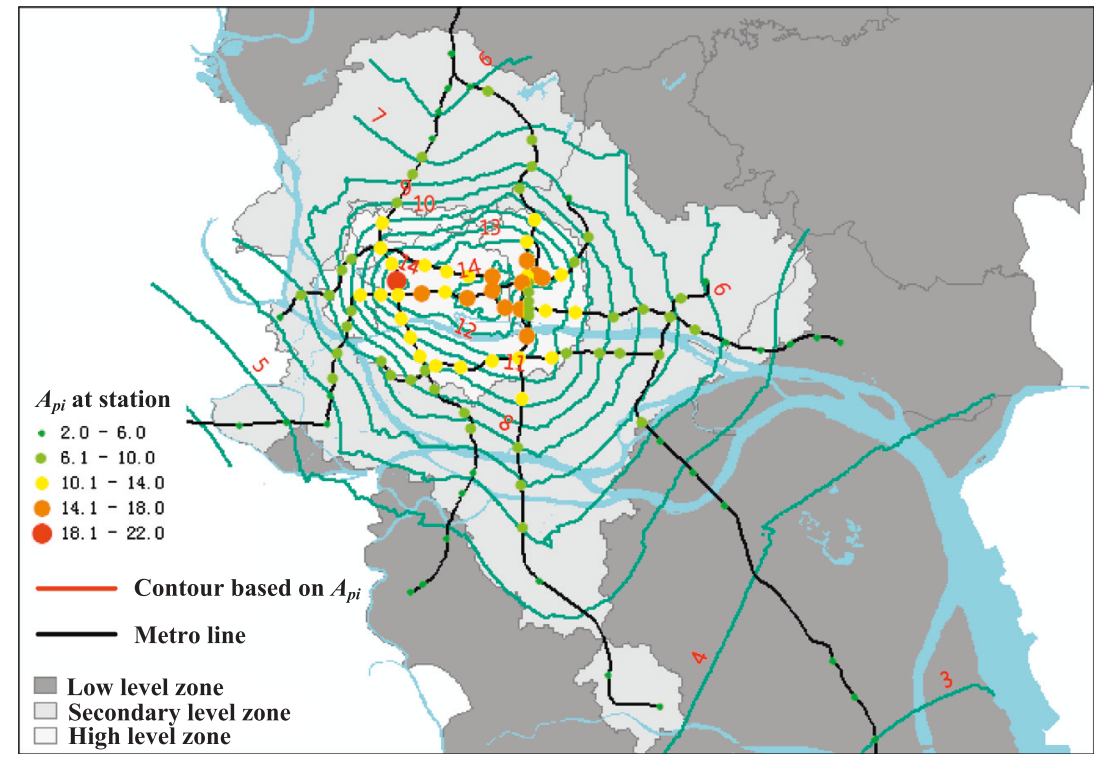

Fig. 10. Urban level zones distribution and the spatial pattern of nodal potential accessibility.

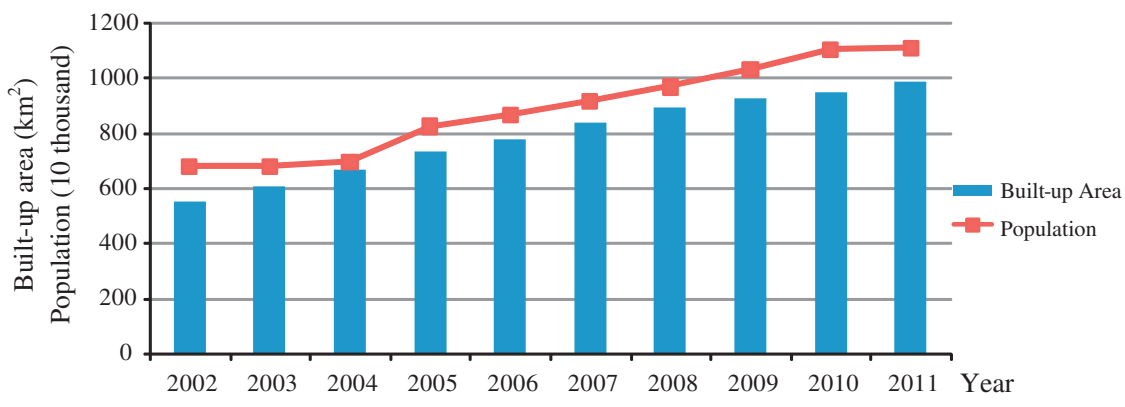

Fig. 11. Increase of the built-up area and population in the city of Guangzhou (2002-2011).

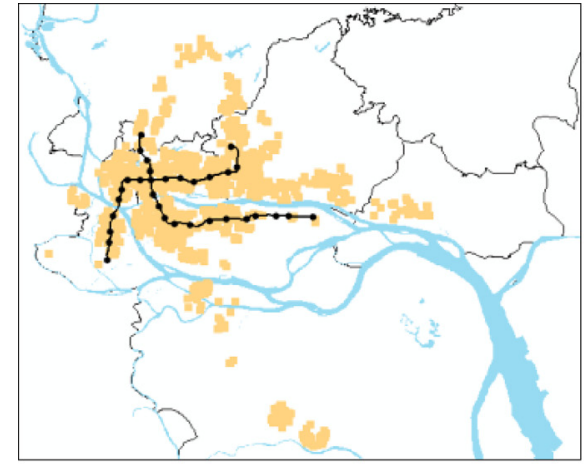

(a) The stage of preliminary construction

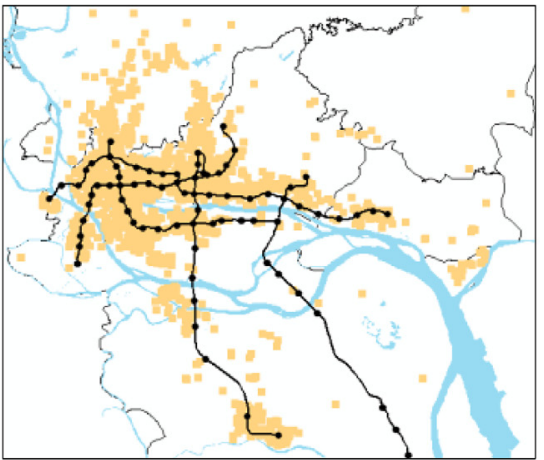

(b) The stage of networking

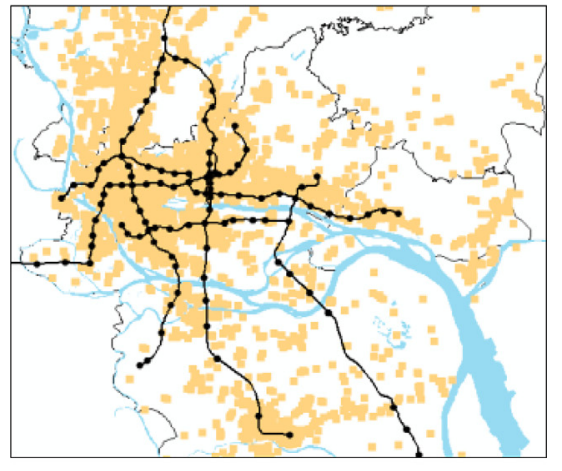

(c) The stage of network intensification

Lengend

- metro station

- metro network

residential and commercial areas

$\square$ district

river

Fig. 12. Expansion of the mixed-use residential and commercial areas

expansion of the distribution of high-density population. All of these reflect the characteristics of transit-oriented development (TOD) in the city of Guangzhou. A TOD neighborhood typically has a center with a transit station or stop (train station, metro station, tram stop, or bus stop), and residential and commercial area is designed to maximize access to public transport, and often 


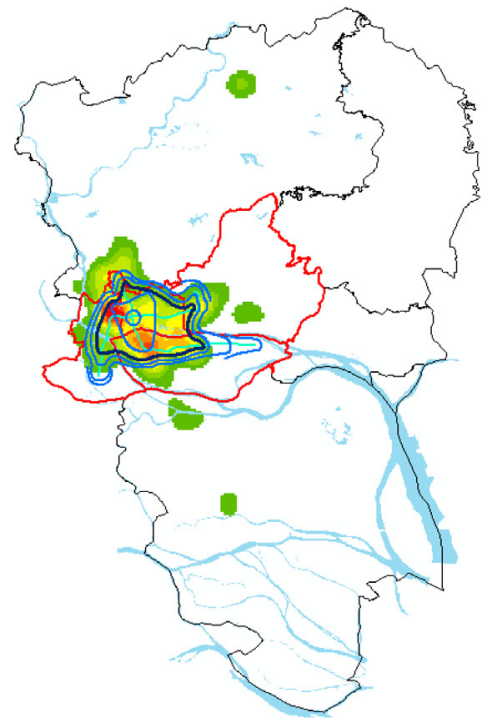

(a) The stage of preliminary construction

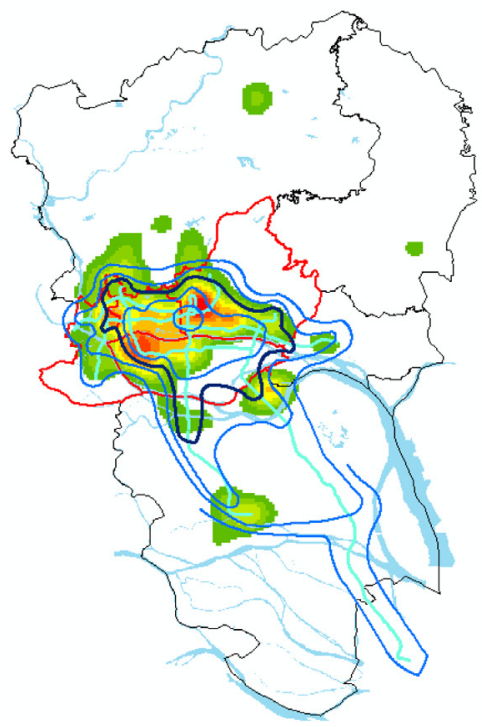

(b) The stage of networking

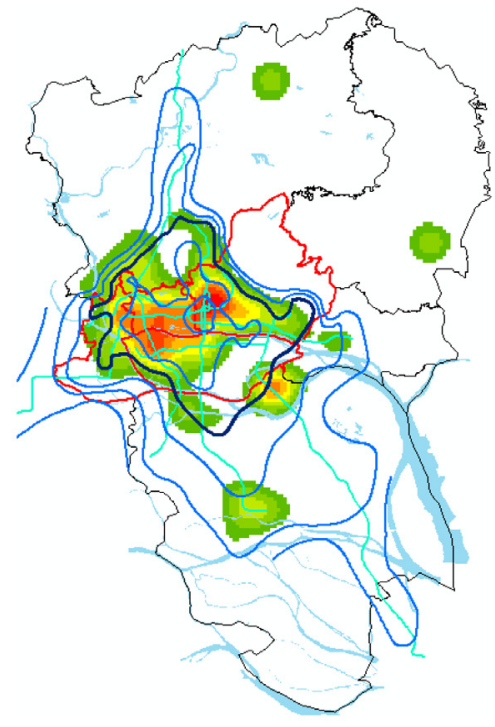

(c) The stage of network intensification
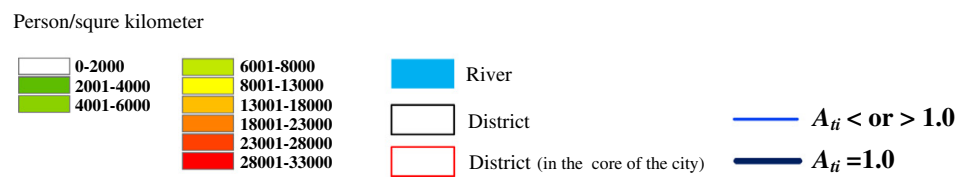

Metro line

Fig. 13. Spatial evolution of the population density and the contours of time-based nodal accessibility in the three stages of metro network development.

incorporates features to encourage transit ridership. Indeed, the improvement of accessibility coefficient at a metro station is one of the underlying factors of population distribution and density change.

The dramatic expansions of the urban mixed-use residential and commercial areas in the city of Guangzhou should lengthen the residents' travel distance. According to the report from the Guangzhou Institute of Transportation Planning (GITP) in 2012, the average travel distance increased from $2.5 \mathrm{~km}$ per person to $10.2 \mathrm{~km}$ per person in the core of the city during 1984-2011. However, the development of metro network system favors the decline of average travel time from $38 \mathrm{~min}$ per person to $25 \mathrm{~min}$ in the same period (GITP, 2012).

\section{Conclusion}

The development of urban transportation systems in large Chinese cities is at a critical stage with the booming of the economy and impressive increase of the population and traffic demand. The objectives of the research presented in this paper are to develop a spatio-temporal modelling approach that qualifies the growth and accessibility of a rapid rail transit network system, and to study the relationship between the evolution of network connectivity and accessibility with urban development.

As experimented in the city of Guangzhou, the research presented in this paper applies four indices of network topological structure, i.e., beta index $(\beta)$, cyclomatic number $(\mu)$, alpha index $(\alpha)$ and gamma index $(\gamma)$ to measure the connectivity of the overall metro network. The results reveal that the spatial connectivity of the overall network is at a relative low level, this stressing the need for an augmentation of the reliability of the connections between the nodes of the network, as well as the number of circuits in the network. A matrix based on travel time evaluates the node accessibility and examines the spatiotemporal evolution of the city of Guangzhou. Spatial interaction between nodes, as well as nodes accessibility, which are derived from nodes attractiveness values and travel time cost between nodes, are analyzed by a potentialbased model. The result demonstrates some dramatic changes of the metro network accessibility values, as well as regional differences. In particular, the network expansion shows that the core of the city is surrounded by areas with highest accessibility gradually expanding outward from the core, and the locations of transfer stations play have significant influences on the network timebased accessibility. Taking into account the respective influence of temporal constraints and node weights (measured by the passenger flow volume in a given period), the potential-based node accessibility variation shows the evolution of the spatial patterns that emerge, and emphasizes the matching with the different levels of regional development, as well as regional accessibility differences within the metropolitan area of the city of Guangzhou.

The close relationship between metro structural properties and urban development is characterized. The results found that the metro network spatio-temporal expansion and accessibility evolution coincided with urban growth, including residential and commercial land-use expansion, and with the evolution of the population distribution. Meanwhile, that urban growth stimulates changes on urban traffic demand and on the environment. This should stimulate and reshape the spatial patterns and structure of the whole urban transportation network. Overall, a better understanding of the metro network accessibility should favor a better understanding of the relationship between metro development and urban growth.

Although potential-based accessibility measures, as well as the time-based matrix analysis developed provide significant information on the transportation network properties and development, urban transportation accessibility should be extended towards a more holistic approach of transportation accessibility, by an integration of multi-modal transportation facilities, as well as additional statistical analysis on socio-economical patterns. This is the direction we plan to consider in further work. 


\section{References}

Ahlfeldta, G.M., Wendlandb, N., 2011. Fifty years of urban accessibility: the impact of the urban railway network on the land gradient in Berlin 1890-1936. Reg. Sci. Urban Econ. 41 (2), 77-88.

Allen, J., Lu, K., 2003. Modeling and prediction of future urban growth in the Charleston region of South Carolina: a GIS-based integrated approach. Conserv. Ecol. 8 (2), 2.

Bharill, R., Rangaraj, N., 2008. Revenue management in railway operations: a study of the Rajdhani Express, Indian railways. Transp. Res. Part A 42, 1195-1207.

Bhatta, B., 2010. Analysis of Urban Growth and Sprawl from Remote Sensing Data. Springer-Verlag, Heidelberg.

Black, W.R., 2003. Transportation: A Geographical Analysis, Guilford, New York.

Blum, U., Gercek, H., Viegas, J., 1992. High-speed railway and the European peripheries: opportunities and challenges. Transp. Res. Part A 26, 211-221.

Bowen, J., 2000. Airline hubs in Southeast Asia: national economic development and nodal accessibility. J. Transp. Geogr. 8, 25-41.

Brotchie, J., 1991. Fast rail networks and socio economic impacts. In: Brotchie, J., Batty, M., Hall, P., Newton, P. (Eds.), Cities of the 21st Century: New Technologies and Spatial Systems. Longman Cheshire, New York.

Brueckner, J., 2000. Urban sprawl: diagnosis and remedies. Int. Reg. Sci. Rev. 23 (2), $160-171$.

Bruinsma, F.R., Rietveld, P., 1993. Urban agglomerations in European infrastructure networks. Urban Stud. 30, 919-934.

Cervero, R., 2003. Road expansion, urban growth, and induced travel: a path analysis. J. Am. Plann. Assoc. 69 (2), 145-163.

Chen, C., Claramunt, C., Ray, C., Tan, J., 2009. A Multiscale and Multimoda Transportation GIS for the City of Guangzhou, Information Fusion and Geographic Information Systems. Lectures Notes in Geoinformation and Cartography, pp. 95-111.

Chen, C., Tan, J., Claramunt, C., Ray, C., 2011. Multiscale and multimodal GIS-T data model. J. Transp. Geogr. 19 (1), 147-161.

Cheng, L.X., 1998. China New City and their positions in the urban network. Acta Geogr. Sin. 53 (6), 481-491.

Cheng, C.X., Zhang, W.C., Chen, J., Cai, J., 2007. Evaluation the accessibility about Beijing's Subways in 2008 based on spatial syntax. J. Geo-Inf. Sci. 9 (6), 31-35.

Deng, Y., Cai, J.-M., Yang, Z.S., Wang, H., 2012. Measuring time accessibility with its spatial characteristics in urban areas of Beijing. Acta Geogr. Sin. 67 (2), 169-178.

Fan, F., Wang, Y., Qiu, M., Wang, Z., 2009. Evaluating the temporal and spatial urban expansion patterns of Guangzhou from 1979 to 2003 by remote sensing and GIS methods. Int. J. Geogr. Inf. Sc. 23 (11), 1371-1388.

Garrison, W.L., 1960. Connectivity of the interstate highway system. In: Paper and Proceedings of the Regional Science Association, vol. 6, pp. 121-137.

Garrison, W.L., Marble, D.F., 1974. Graph theoretic concepts. In: Michael, E., Hurst, Eliot (Eds.), Transportation Geography: Comments and Readings. McGraw, NY, pp. 58-80.

Geertman, S.C.M., Ritsema, V., Eck, J.R., 1995. GIS and models of accessibility potential: an application in planning. Int. J. Geogr. Inf. Syst. 9 (1), 67-80.

GITP (Guangzhou Institute of Transportation Planning), 2012. Report: Guangzhou Transportation Development Yearbook: 2012. Guangzhou Institute of Transportation Planning, Guangzhou, China, 80p.

GMC (Guangzhou Metro Company), 2012. Guangzhou Metro Development Yearbook (2012). Guangzhou Metro Company, Guangzhou, China, 30p.

Gutiérrez, J., 2001. Economic potential and daily accessibility: an analysis of the accessibility impact of the high-speed line Madrid-Barcelona-French Border. J. Transp. Geogr. 9, 229-242.

Gutiérrez, J., Urbano, P., 1996. Accessibility in the European Union: the impact of the trans-European road network. J. Transp. Geogr. 41, 15-25.

Hansen, W.G., 1959. How accessibility shapes land use. J. Am. Inst. Planners 25, 7376.

Jackson, K., 1985. Crabgrass Frontier: The Suburbanization of the United States. Oxford University Press, New York.

Jeong, S.J., Lee, C.-G., Bookbinder, J.H., 2007. The European freight railway system as a hub-and-spoke network. Transp. Res. Part A 41, 523-536.

Jiang, Y., Zegras, C., Shomik Mehndiratta, S., 2012. Walk the line: station context corridor type and bus rapid transit walk access in Jinan, China. J. Transp. Geogr. $20,15-22$.

Jin, C., Lu, Y.L., Zhang, L., 2009. An analysis of accessibility of scenic spots based on land traffic network: a case study of Nanjin. J. Geogr. Res. 28 (1), 246-258.
Johnson, J.H., 1967. Urban Geography: An Introductory Analysis. Pergamon Press, Oxford.

Keeble, D., Offord, J., Walker, S., 1988. Peripheral Regions in a Community of Twelve. Office for Official Publications of the European Communities, Brussels/ Luxembourg.

Kreutzberger, E.D., 2008. Distance and time in intermodal goods transport networks in Europe: a generic approach. Transp. Res. Part A 42, 973-993.

Li, S.M., Shum, Y.M., 2001. Impacts of the national trunk highway system on accessibility in China. J. Transp. Geogr. 9, 39-48.

Lin, L., Lu, D.D., 2011. Major transportation facility and spatial structure evolution in Guangzhou. Sci. Geogr. Sin. 31 (9), 1050-1055.

Linneker, B., Spence, N.A., 1992. Accessibility measures compared in an analysis of the impact of the M25 London orbital motorway on Britain. Environ. Plann. A $24,1137-1154$

Lutter, H., Pütz, T., Spangenberg, M., 1992. Accessibility and Peripherality of Community Regions: The Role of Road Long Distance Railway and Airport Networks. Commission of the European Communities, Brussels.

Mao, J.X., Yan, X.P., 2005. Study on mutual mechanism between urban transport system and urban space pattern: a case study of Guangzhou. Chin. J. Urban Transp. 29 (5), 45-50.

Marína, A., García-Ródenas, R., 2009. Location of infrastructure in urban railway networks. Comput. Oper. Res. 36 (5), 1461-1477.

Mavoa, S., Witten, K., McCreanor, T., O'Sullivan, D., 2012. GIS Based destination accessibility via public transit and walking in Auckland, New Zealand. J. Transp. Geogr. 20, 15-22.

Meyer, M.D., Miller, E.J., 2001. Urban Transportation Planning, second ed. McGraw Hill, New York.

Millot, M., 2004. Urban growth, travel practices and evolution of road safety. J. Transp. Geogr. 3, 207-218.

Morris, J.M., Dumble, P.L., Wigan, M.R., 1979. Accessibility indicators for transport planning. Transp. Res. Part A 13, 91-109.

Murayama, Y., 1994. The impact of railways on accessibility in the Japanese urban system. J. Transp. Geogr. 2, 87-100.

Parker, A., 1995. Patterns of federal urban spending: central cities and their suburbs, 1983-1992. Urban Affairs Rev. 31 (2), 184-205.

Pirie, G.H., 1981. The possibility and potential of public policy on accessibility. Transp. Res. Part A 15, 377-381.

Priemus, H., Nijkamp, P., Banister, D., 2001. Mobility and spatial dynamics: an uneasy relationship. J. Transp. Geogr. 3, 167-171.

Rühl, A., 1991. Financial relations between European railways for their international services. Transp. Res. Part A 25, 203-207.

Salze, P., Banos, A., Oppert, J.M., et al., 2011. Estimating spatial accessibility to facilities on the regional scale: an extended commuting-based interaction potential model. Int. J. Health Geogr. 10, 2.

Siming, L., Yiman, S., 2001. Impacts of the national trunk highway system on accessibility in China. J. Transp. Geogr. 1, 39-48.

Sohn, J., 2006. Evaluating the significance of highway network links under the flood damage: an accessibility approach. Transp. Res. Part A 40, 491-506.

Spence, N.A., Linneker, B., 1994. Evolution of the motorway network and changing levels of accessibility in Great Britain. J. Transp. Geogr. 4, 247-264.

Statistics Bureau of Guangzhou, 2012. Guangzhou Statistical Yearbook, 2012 Guangzhou, China.

Stewart, J.Q., 1941. An inverse distance variation for certain social influences. Science 93, 89-90.

USDE (United States Department of Environment), 1996. Policy and Procedure Guidelines, PPG 6.

Wang, J., Jin, F., Mo, H., Wang, F., 2009. Spatiotemporal evolution of China's railway network in the 20th century: an accessibility approach. Transp. Res. Part A 43, $765-788$.

Xiang, Q.-N., Chen, Y.-H., 2010. Study on the interaction between railway transport accessibility and regional economic development. J. Railway Transp. Econ. 32 (11), 69-72.

Yan, X.P., Mao, J.X., 2004. The mutual relationship between urban transport system and land use in highly-densely developed cities: a case study of Guangzhou. Acta Geogr. Sin. 59 (5), 643-652.

Zhang, L., Lu, Y.L., 2006. Assessment on regional accessibility based on land transportation network: a case study of the Yangtze River Delta. Acta Geogr. Sin. $61(12), 1235-1246$

Zhou, S.H., Yan, X.P., 2005. The relationship between urban structure and traffic demand in Guangzhou. Acta Geogr. Sin. 60 (1), 131-142. 